\title{
A NARRATIVA BIOGRÁFICA NO DEBATE ACADÊMICO CONTEMPORÂNEO: UMA CONTRIBUIÇÃO BIBLIOGRÁFICA ${ }^{1}$
}

MAURO HENRIQUE MIRANDA DE ALCÂNTARA

http://orcid.org/0000-0002-4338-6869

Instituto Federal de Rondônia - Campus Cacoal

RESUMO O sucesso editorial do gênero biográfico não se reflete diretamente na academia. Por vezes, esse tipo de narrativa fora negligenciado ou diminuído em várias áreas do conhecimento e, principalmente, na História. Contudo, diversos estudos vêm alterando essa perspectiva sobre a biografia, possibilitando a ampliação dos usos biográficos na História e em variadas ciências. Partindo de uma análise bibliográfica, buscamos elucidar quais são os debates acadêmicos atuais sobre este gênero, quais os principais usos dessa narrativa neste ambiente, e quais as limitações e problematizações da biografia na contemporaneidade, principalmente no campo historiográfico. Ao final, pudemos identificar um avanço epistemológico no gênero biográfico, conseguindo este ter maior autonomia, principalmente frente à historiografia, contudo, ainda há um longo caminho para quebrar tabus em torno dessa forma de narrativa.

Palavras-chave: Biografia. Narrativa. Academia. Epistemologia.

\section{ABSTRACT THE BIOGRAPHICAL NARRATIVE IN CONTEMPORARY ACADEMIC DEBATE: A BIBLIOGRAPHICAL CONTRIBUTION}

The editorial success of the biographical genre is not directly reflected in academia. Sometimes this type of narrative has been neglected or diminished in various areas of knowledge, and especially in history. However, several studies have changed this perspective on biography, allowing the expansion of biographical uses in History and in various sciences. Starting from a bibliographical analysis, we seek to elucidate what are the current academic debates about this genre, what are the main uses of this narrative in this environment,

1 Agradeço à Fundação Rondônia de Amparo ao Desenvolvimento das Ações Científicas e Tecnológicas e à Pesquisa do Estado de Rondônia (Fapero), à Coordenação de Aperfeiçoamento de Pessoal de Nível Superior (Capes) e ao Instituto Federal de Rondônia (IFRO) pelo financiamento para o desenvolvimento da pesquisa que resultou este artigo. 
and what are the limitations and problematizations of contemporary biography, especially in historiography. In the end, we were able to identify an epistemological breakthrough in the biographical genre, achieving greater autonomy, especially compared to historiography, however, there is still a long way to break taboos around this form of narrative.

Keywords: Biography. Narrative. Academy. Epistemology.

\section{RESUMEN LA NARRATIVA BIOGRÁFICA EN EL DEBATE ACADÉMICO CONTEMPORÁNEO: UNA CONTRIBUCIÓN BIBLIOGRÁFICA}

El éxito editorial del género biográfico no se refleja directamente en la academia. A veces este tipo de narrativa se ha pasado por alto o disminuido en diversas áreas del conocimiento, y especialmente en la historia. Sin embargo, varios estudios han cambiado esta perspectiva sobre la biografia, permitiendo la expansión de los usos biográficos en la Historia y en diversas ciencias. Partiendo de un análisis bibliográfico, buscamos aclarar cuáles son los debates académicos actuales sobre este género, cuáles son los principales usos de esta narrativa en este entorno y cuáles son las limitaciones y problematizaciones de la biografia contemporánea, principalmente en el campo historiográfico. Al final, pudimos identificar un avance epistemológico en el género biográfico, logrando una mayor autonomía, especialmente en comparación con la historiografia, sin embargo, todavía hay un largo camino para romper los tabúes en torno a esta forma de narrativa.

Palabras clave: Biografía. Narrativa. Academia. Epistemología.

\section{Introdução}

A origem do vocábulo "biografia" remonta a antiguidade, mais precisamente à Grécia. ${ }^{2}$ Segundo Plutarco, significava "escrita da vida de alguém pertencente à esfera pública ou privada" (XAVIER; VASCONCELOS; VALE XAVIER, 2018,

2 Contudo, segundo Xavier, Vasconcelos e Vale Xavier, "há autores que defendem ser a biografia oriunda das inscrições feitas pelo rei da Pérsia, que teria escrito sua autobiografia numa rocha, a 300 pés, na qual destacou seu próprio heroísmo" (2018, p. 1018). Contudo, manteremos o surgimento da palavra biográfica e do gênero narrativo aos gregos na antiguidade, pois é a partir dela que se desenvolve a discussão historiográfica contemporânea no mundo ocidental. p. 1018). Na antiguidade, a narrativa biográfica ultrapassava os limites do relato histórico e verídico de uma vida, equilibrando-se "entre verdade histórica e verdade literária" (LORIGA, 2011, p. 18), sem a preocupação em construir uma narrativa histórica, e sim um texto narrado de um determinado personagem que fizera parte dela.

$\mathrm{Na}$ idade média construiu-se um modo de narrar vidas "nas quais os acontecimentos da vida do indivíduo" eram "totalmente interpretadas pelo quadro estrutural de sua existência 
coletiva e pelas representações genéricas de sua função" Na época moderna, dá-se o inverso: surge "um modo de construção biográfica pelo qual o indivíduo tende a outorgar a si mesmo sua lei de constituição e a encontrar em sua experiência pessoal as fontes de seu desenvolvimento". E é este tipo de narrativa que construiu o "arquétipo genérico da individualidade moderna" (DELORY-MOMBERGER, 2011, p. 336).

É a partir deste cenário (após o século XVII) que a palavra "biografia" passou a designar um relato verdadeiro sobre uma vida, contrapondo narrativas que idealizavam e rebuscavam em demasia os personagens biografados (LORIGA, 2011). E a partir de então, sofreu diversas mudanças.

O século XIX e parte do XX acabou por rejeitá-la. A autonomia da história e a sua busca por se tornar ciência, fizera com que o estatuto biográfico fosse questionado e desvalorizado (DOSSE, 2009), visto como um gênero menor e, principalmente, pouco confiável para se compreender as estruturas da sociedade. Porém, a necessidade de se entender as relações entre indivíduo e sociedade, ou como as estruturas agem nas individualidades, deu força ao projeto biográfico a partir da década de 1980 (LEVILLAIN, 2003).

Os anos 2000, segundo Pineau, ampliou os "neologismos" e utilização do termo "biografia": "biografização, biocognitivo, bioético, biopolítico". Essas nomenclaturas configuram-se como "um indicador linguístico da construção de novos espaços conceituais", o que corrobora para "trabalhar o aumento multiforme e inédito desses problemas vitais" (2006, p. 339). Arfuch (2010) escreve que o espaço biográfico contemporâneo incorpora tanto os tipos narrativos clássicos (biografias, autobiografias, confissões, memórias, diários íntimos, correspondências), quanto os atuais (entrevistas, conversas, perfis, retratos, anedotários, teste- munhos históricos, histórias de vida, relatos de autoajuda, variantes de show - talk show, reality show), buscando atender a um público heterogêneo e disperso, que cada vez mais consomem narrativas biográficas (ARFUCH, 2010, p. 15; 37).

Esse consumo demonstra o sucesso do gênero na atualidade, diante disso, nos perguntamos: como a academia vem debatendo/ questionando/estudando sobre esse gênero? Quais são os usos do biográfico em estudos historiográficos contemporâneos? E a questão da narrativa? É possível narrar sobre uma vida? Como os(as) historiadores(as) têm lidado com esse tema? Essas são questões que buscaremos responder neste artigo, a partir de uma análise bibliográfica contemporânea.

\section{Debates sobre a narrativa biográfica na contemporaneidade}

Burdiel (2014b), foi a organizadora do dossiê Los retos de la biografía publicado na Revista Ayer. Logo na capa da edição identificamos os objetivos da coletânea e como a biografia tem sido vista/pensada no mundo acadêmico:

A reflexão sobre a biografia foi enriquecida nos últimos anos, respondendo às críticas de seus usos mais convencionais. O impacto das mudanças culturais da modernidade na consideração do biográfico, a ampliação do que é tradicionalmente definido como político, os novos caminhos da história sociocultural, a importância da história das mulheres e as possibilidades da biografia coletiva (ASOCIACIÓN DE HISTÓRIA CONTEMPORÁNEA, 2014b, p. 1, tradução nossa). ${ }^{3}$

Dessa síntese, podemos compreender al-

3 "La reflexión sobre la biografía se ha enriquecido en los últimos años, respondiendo a las críticas sobre sus usos más convencionales. Se discute aquí el impacto de los cambios culturales de la modernidad en la consideración de lo biográfico, el ensanchamiento de lo tradicionalmente definido como político, los nuevos recorridos de la historia sociocultural, la importancia de la historia de las mujeres y las posibilidades de la biografía colectiva". 
guns sintomas e possibilidades da biografia na atualidade: 1 - é uma forma de escrita critica$\mathrm{da}$, devido aos seus usos mais convencionais; 2 - tem sido objeto de estudo na academia, por isso o enriquecimento de reflexões sobre ela nos últimos anos; 3 - a modernidade impactou em mudanças culturais, o que afetou diretamente esse gênero; 4 - há novos usos para esse tipo de escrita: passando por uma nova leitura do político e do sociocultural, e a evidenciação da história das mulheres e da possibilidade de estudos coletivos biográficos.

Burdiel nessa apresentação, detalha em algumas linhas o que ela chama de contribuição biográfica para a historiografia, ao estabelecer "chaves úteis para conversas historiográficas comuns sobre a necessidade de atravessar fronteiras geográficas, políticas e disciplinares para melhor aproximar a complexidade e a pluralidade do passado" (BURDIEL, 2014b, p. 14). Ela visualiza nessa forma de escrita, uma forma atualizada de escrever a história, por se aproximar qualitativamente, da complexidade e pluralidade do passado, e, também, por cruzar as fronteiras geográficas. Parece-nos que Burdiel compreende que biografar é ter maior dinamismo e capacidade de integrar o todo, a partir do estudo da singularidade dos sujeitos:

O relevante na atual reflexão interdisciplinar e internacional sobre o que é ou deveria ser uma biografia, é permitir que os historiadores trabalhem em um cenário de perguntas e respostas mais complexas e conscientes de seus desafios, do seu alcance, mas também das limitações da história biográfica. Ou seja, daquela forma de abordagem do passado que, focada nas trajetórias individuais, assume como um todo e cada um dos problemas que a história apresenta como disciplina, aumentando a tensão analítica entre as partes e o todo, o indivíduo e o coleti-

4 “[...] claves útiles de conversación historiográfica común sobre la necesidad de cruzar fronteras geográficas, políticas y disciplinares para aproximarse mejor a la complejidad y la passadoade del passado". vo, o particular e o geral, liberdade e a necessidade (BURDIEL, 2014b, p. 14). ${ }^{5}$

Para essa estudiosa, a investigação biográfica permite, de forma hermenêutica, aproximação entre passado e presente, entre o singular e o plural, entre os iguais e os diferentes, ou seja, para ela, a biografia é um lugar privilegiado para identificar e apresentar as realidades históricas e a causalidade histórica. Por essa via, compreendemos que ela defende a biografia como uma escrita historiográfica, senão superior, ao menos mais adequada e adaptada aos novos tempos.

Sobre os problemas que a escrita biográfica traz em sua composição, tais como a impossibilidade de narrar sobre uma vida e a excessiva dependência dos acontecimentos/ eventos nesse tipo narrativo, Burdiel, no artigo intitulado "Historia politica y Biografia: mas allá de las fronteras", relata que alguns dos fantasmas, do chamado retorno biográfico, foram superados a partir de reflexões que há tempos a historiografia vem realizando desde sua constituição como disciplina (BURDIEL, 2014a, p. 53-54). Portanto, essas preocupações são partes integrantes do conhecimento histórico, não reclusas à biografia.

Outra questão que aborda, e que é importante somarmos a esta discussão, relaciona-se à ampliação do que chamamos de biográfico. Mais do que narrar sobre uma vida, do nascimento à morte do sujeito histórico, são vistas também como uma abordagem biográfica todas as formas de escritas sobre o "eu": "como

5 “Lo relevante es que la reflexión interdisciplinar e internacional actual sobre qué cosa es o debería ser una biografía permite a los historiadores trabajar en un escenario de preguntas y respuestas más complejo y consciente de sus retos, del alcance, pero también de las limitaciones, de la historia biográfica. Es decir, de aquella forma de aproximación al pasado que -centrada en trayectorias individuales- asume como propios todos y cada uno de los problemas que se plantea la historia como disciplina, agudizando la tensión analítica entre las partes y el todo, lo individual y lo colectivo, lo particular y lo general, la libertad y la necesidad". 
diários, memórias, cartas, autobiografias, biografias ou mesmo anotações de natureza muito menos elaborada ou informal" (BURDIEL, 2014a, p. 54) ${ }^{6}$. Com essa gama de possibilidades, escreve que se alargam, também, os usos das biografias:

Em sua formulação mais interessante, o termo tem como objetivo questionar a nítida separação entre o que é feito ao escrever uma biografia, autobiografia ou memórias; aumentar a autorreflexividade dos autores sobre seu próprio envolvimento no trabalho; demonstrar a necessidade de narrar a si mesmo para negociar, estabelecer ou contestar identidades atribuídas socialmente e, enfim, promover o reconhecimento de que, potencialmente, todas as vidas e todas as histórias de vida são interessantes para o historiador. Em seu uso mais banal, e na melhor das hipóteses, atua como um guardachuva confortável e que procura fugir das conotações negativas do termo biografia. Na pior das hipóteses, tende a promover um excesso de simpatia e evitar a reflexão sobre as diferenças substanciais que existem, epistemológica e metodologicamente, entre as várias formas de escrita 'pessoal' e os mecanismos de atribuição de significado histórico a elas (BURDIEL, 2014a, p. 53-54 $)^{7}$

Narrar sobre uma vida é, somente, uma das utilidades da escrita biográfica para o(a) histo-

6 “[...] como los diarios, las memorias, las cartas, las autobiografias, las biografias o, incluso, anotaciones de carácter mucho menos elaborado o informal" (BURDIEL, 2014a, p. 54).

7 "En su formulación más interesante, el término pretende cuestionar la separación tajante entre lo que se hace al escribir una biografia, una autobiografia o unas memorias; potenciar la autorreflexividad de los autores sobre su propia implicación en el trabajo; demostrar la necesidad de narrar el yo para negociar, asentar o impugnar las identidades socialmente atribuidas y favorecer, en suma, el reconocimiento de que, en potencia, todas las vidas y todos los relatos de vida son interesantes para el historiador. En su utilización más banal, y en el mejor de los casos, actúa como un paraguas cómodo y al uso que busca alejarse de las connotaciones negativas del término biografia. En el peor, suele propiciar un exceso de simpatía y evitar la reflexión sobre las sustanciales diferencias que existen, en lo epistemológico y metodológico, entre las diversas formas de escritura 'personal' y los mecanismos de atribución de significado histórico a las mismas". riador(a), principalmente, quando se trata de uma análise de história política, segundo essa historiadora. É possivel questionar as motivações para as construções autobiográficas e diários; buscar identificar nas autorreflexões construções temporais e históricas, possibilitando compreender o social e/ou o político; ao analisar biografias que persistem com as tendências de narrativas de eventos e ações dos sujeitos, criam-se possibilidades de identificar nessas obras problemas epistemológicos e metodológicos, como, também, de compreender como determinadas narrativas constroem significados e realidades históricas, mesmo com usos limitados ou não adequados para a escrita da história, para essa pesquisadora.

Em 2018, outro dossiê buscou debater sobre as questões biográficas. Dessa vez, uma publicação no campo das linguagens. Moreira e Caballé (2018) organizaram o volume da revista Letras de Hoje, com intuito de abordar perspectivas teóricas e metodológicas do fazer biográfico no campo literário. Logo na apresentação do volume, é possivel observar convergências entre a História e a Literatura junto a essa forma de escrita. As autoras apontam a "natureza interdisciplinar" da biografia, levando-a requerer de outras disciplinas base contextual e teórica que satisfaçam "as exigências analíticas e de conhecimento próprias do trabalho intelectual" (MOREIRA; CABALLÉ, 2018, p. 187). Por essas palavras, percebemos que as professoras partem de uma perspectiva acadêmica para pensar o trabalho biográfico. 0 sucesso editorial do gênero, somado à disseminação de biografias para diversos meios de comunicação, pressiona a academia a pensar/ refletir sobre esse tipo de escrita:

0 interesse pelas vidas reais se acha presente em todos os meios de comunicação (cinema, televisão, imprensa, internet), monopoliza as novidades editoriais e por fim está entrando no mundo acadêmico como uma disciplina que, 
incrustada entre a história e a criação literária, facilita a interpretação da vida humana individual, passada ou presente. No entanto, o atraso ou a lentidão com que se está produzindo essa incorporação, ao menos no contexto iberoamericano, torna-se um pouco decepcionante, dada à imensa contribuição que a escritura biográfica tem proporcionado ao mundo do conhecimento e da cultura. (MOREIRA; CABALLÉ, 2018, p. 187)

Essa inquietação e decepção das autoras em relação à recepção do gênero biográfico no mundo acadêmico é também semelhante ao verificado por historiadores/as. Principalmente àqueles(as) que se dedicam a pesquisar ou escrever biografias. Todavia, apesar das lamúrias dos(as) pesquisadores(as), pouco se avançou em relação à construção de perspectivas teóricas e metodológicas no campo historiográfico. Por exemplo, ainda são poucos os cursos de graduação e pós-graduação espaIhados pelo Brasil, que ofertam disciplinas e/ ou cursos com o objetivo de discutir, debater e principalmente, sistematizar conceitos, teorias e metodologia para esse gênero. ${ }^{8}$

Essa ausência da discussão em torno da questão biográfica na academia reduz as possibilidades de um uso organizado e sistemático dessa forma narrativa. Moreira e Caballé,

8 Em uma rápida e aleatória pesquisa em grades curriculares dos cursos de graduação e pós-graduação das universidades: Universidade de São Paulo (USP), Universidade Federal do Mato Grosso (UFMT), Universidade Federal do Rio de Janeiro (UFRJ), Universidade Federal Fluminense (UFF), Universidade Estadual de Campinas (UNICAMP), Universidade Federal Rural do Rio de Janeiro (UFRRJ) e Universidade Federal de Pernambuco (UFPE), há pouquíssimas disciplinas/programas que abordam a temática biográfica. Na área da História, somente os programas de pós-graduação em História da UFRJ, (duas disciplinas) da UFF (uma) e da USP (uma) disponibilizaram disciplinas no ano de 2018. Em outras áreas, encontramos mais duas disciplinas ofertadas nesta instituição no campo literário. A Universidade Federal do Ceará (UFC), em seu Programa de Pós-Graduação em Educação, ofertou no semestre 2019.1, uma disciplina neste campo de pesquisa. A Universidade do Estado da Bahia (UNEB), através do Programa de Pós-graduação em Educação e Contemporaneidade, ofertou nos semestres 2018.2 e 2019.1 a Disciplina Abordagem (Auto)biográfica: perspectivas epistemológicas, ao concentrar discussões sobre o campo da abordagem biográfica. inclusive, compartilham desse pensamento e vão além, identificam na Teoria Literária parecida letargia:

[...] frente à emergência teórica da autobiografia como escritura que propõe problemas medulares em relação à verdade, a criação da personagem ou a autoreferencialidade, a biografia é uma escritura que apenas mereceu interesse para a teoria literária, e muito pouco para a historiografia, em que pese manejar conceitos e ferramentas fundamentais para sua hermenêutica e de grande interesse epistemológico, como o uso que faz das fontes, a seleção das fontes, o ponto de vista do biógrafo, a relação biógrafo-biografado. 0 fato mais elementar de toda a biografia, o conhecimento da personagem a ser biografada, abre por si uma problemática enorme, pois a tarefa de investigar, que pode ser um trabalho mais ou menos opcional em outras disciplinas e escrituras, é o coração da biografia, o que verdadeiramente distingue a prática das chamadas lifes-writing da escritura de ficção. (MOREIRA; CABALLÉ, 2018, p. 187)

As professoras defendem que o trabalho biográfico possui, em si, toda a complexidade de um trabalho acadêmico. Mesmo assim, as pesquisas, leituras e estudos sobre ele foram tangenciados por esse público. Para elas, esse desprezo para com o gênero impediu o desenvolvimento de trabalhos que apresentassem bases teóricas e metodológicas para o melhor aperfeiçoamento dessa perspectiva de pesquisa e escrita. Há campo e necessidade de avançar em tais temas.

Esses novos usos, problemas e possibilidades da narrativa biográfica discutidos nos textos anteriores foram resultantes, de certa forma, de uma nova ótica de ver o sujeito histórico. No texto "How new is the new biography? Some remarks on the misleading term's past and presente", Cymbrykiewicz (2018) apresenta importante discussão sobre o que é o "novo" na chamada "new biography".

Ela buscou, a partir de uma contextualização histórica sobre a escrita biográfica na 
língua inglesa, compreender as modificações, alterações e novidades quanto a esse novo. Cymbrykiewicz (2018) conceitua as diferentes estruturas biográficas. Primeiramente, ela explica o que entende por biografia tradicional ou clássica, que é a estrutura de origem greco-romana, na qual uma narrativa persegue a trajetória de um protagonista (geralmente, um personagem de destaque público) desde o seu nascimento até sua morte, realizando, assim, a representação de uma vida, por fins pedagógicos morais.

A autora identificou no século XVIII, mais precisamente no ano de 1744 , na publicação da biografia sobre o poeta inglês Richard Savage, escrita por Samuel Johnson, uma obra que não partira desta estrutura clássica. Afinal, Savage não obtivera grande sucesso como poeta e ainda possuía uma má reputação na sociedade, com direito a registros criminais e de escândalos. Cymbrykiewicz argumenta que a biografia de uma personalidade como Savage caracteriza um processo de "desmitologização e redefinição de um sujeito ideal"

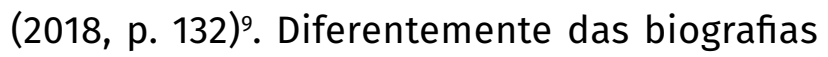
tradicionais, essa narrativa de Samuel Johnson realiza o trabalho inverso: apresentando um homem comum, com seus erros, defeitos e seu carisma. Por fim, a natureza humana do biografado.

James Boswell, discípulo de Samuel Johnson, segundo a autora, deu continuidade ao trabalho do mestre e trouxe novidades para a escrita biográfica. Na biografia que Boswell escreveu sobre Johnson, narra sobre o período no qual acompanhou os seus trabalhos, durante cerca de 20 anos. Dessa maneira, ignora outra importante característica das biografias clássicas, segundo Cymbrykiewicz (2018): a cronologia do nascimento à morte.

Cymbrykiewicz (2018) descreve que entre o

9 “[...] demythologization and redefinition of an ideal subject". final do século XVIII e o final do XIX, a novidade trazida por Johnson-Boswell foi, praticamente, ignorada nas escritas biográficas. A Era Vitoriana resgatou, segundo ela, a biografia clássica, apresentando narrativas hagiográficas e/ou acríticas sobre os personagens. Retomando o interesse em vidas exemplares para usos didáticos-sociais.

No começo do século $X X$, principalmente devido aos efeitos da primeira guerra mundial, fizeram com que a biografia de estilo vitoriana passasse a ser criticada e entrasse em desuso. Uma nova forma de narrar vidas passou a ser necessária, como "remédio, ou pelo menos um antídoto, para a crueldade da guerra que privou um ser humano de qualquer valor" (CYMBRYKIEWICZ, 2018, p. 134) ${ }^{10}$. Para além das fronteiras inglesas, essa nova forma de pensar/narrar sobre vidas também apareceu em países participantes da guerra: Alemanha e França, segundo a autora.

E nessa nova forma de escrever biografia, Cymbrykiewicz destaca as novidades dos trabalhos Lytton Strachey, no começo do século XX. Quatro características do estilo biográfico de Strachey, para a historiadora, exemplificam o estilo "new biography":

Antes de tudo, essa seleção de biografias de quatro personalidades eminentes da era vitoriana, o cardeal Manning, Florence Nightingale, Thomas Arnold e Charles Gordon, está desmerecendo sua atitude em relação às biografias e, como observa Nigel Hamilton apropriadamente, é "brilhantemente eficaz em destruir reputações vitorianas". Em segundo lugar, seu volume é surpreendentemente modesto, em oposição às enunciações detalhadas e longas dos biógrafos vitorianos, ou, nesse caso, de Johnson e Boswell. Terceiro, evita a proclamada invisibilidade do biógrafo na representação da vida, destacando, por sua vez, a manifestação de sua própria personalidade. Quarto, é divertido e bem-humorado ao descrever seus assuntos, e

10 “[...] remedy, or at least an antidote, to the gruesomeness of the war which deprived an individual human being of any value". 
seu tom sardônico e "desapego irônico" (CYMBRYKIEWICZ, 2018, p. 135)"11

A biografia a la Strachey privilegiou obras irônicas/sarcásticas, pequenas e, principalmente, com a presença do biógrafo na narrativa. Este passou a ser valorizado e não mais renegado a um narrador ausente e, necessariamente, imparcial. Dessa maneira, as biografias tinham como objetivo realizar críticas sociais e políticas. Contrariar a ordem vigente mais do que desmitologizar ou humanizar a narrativa sobre vidas, proposta por Johnson-Boswell.

Litton Strachey e suas irônicas biografias, apesar de inovadoras, não tinham um método para sua elaboração, segundo a autora. E fora justamente essa a principal preocupação de Leon Edel: criar uma metodologia biográfica. Em sua obra Writing Lives: Principia Biographica, publicada em 1984, trouxe a preocupação de estabelecer regras biográficas. 0 principal objetivo de uma obra biográfica para Edel, segundo Cymbrykiewicz (2018, p. 137), era “decifrar a 'pessoa verdadeira' por trás das obras, é por isso que ele se concentrou em encontrar a chave para as 'verdades mais profundas' e discernir 'a figura debaixo do tapete"'12. Ao invocar a necessidade do biógrafo em procurar as verdades mais profundas e discernir a figura sob o tapete, Edel, mais do que preocupado em narrar as verdades sobre o personagem biografado, está interessado em trazer para a

11 "First of all, this selection of biographies of four eminent personalities from the Victorian age, cardinal Manning, Florence Nightingale, Thomas Arnold and Charles Gordon, is debunking in its attitude towards the biographies and, as Nigel Hamilton aptly observes, is "brilliantly effective in smashing Victorian reputations". Secondly, its volume is surprisingly modest, as opposed to the detailed and lengthy enunciations of the Victorian biographers, or, for that matter, Johnson's and Boswell's. Thirdly, it shuns the biographer's proclaimed invisibility in life-depiction, excelling, in turn, in manifesting his own personality. Fourthly, it is amusing and humorous in describing its subjects, and its sardonic tone and "ironic detachment".

12 "[...] deciphering the "true person" behind the works, that is why he focused on finding the key to "the deeper truths" and discerning "the figure under the carpet". superficie os interesses, as verdades do biógrafo em narrar sobre o personagem, defendendo, portanto, que a biografia deveria assumir sua forma artística, para que pudesse usar da ficção como criadora de realidades.

Outra perspectiva retratada por Cymbrykiewicz é da historiadora Burr Margadant. Interessada em pesquisas sobre o feminismo, essa autora defende que a biografia pode ser um locus privilegiado para apresentar o protagonismo das vidas dos sujeitos, no caso das muIheres (2018, p. 139). Mais do que narrar sobre o ambiente, o período, Margadant, defende que o importante é apresentar/narrar as escolhas/ ações dos personagens, pois assim, se colabora na construção de uma identidade subjetiva. A crítica de Cymbrykiewicz a essa perspectiva é que ela não privilegia a construção de uma "new biography", apenas utiliza de métodos e concepções existentes sobre a narrativa biográfica, para dar voz a personagens desconhecidos, permitindo apresentar uma construção identitária.

Após apresentar uma análise histórica/ conceitual sobre a "new biography", perpassando pelos(as) autores(as) os(as) quais Cymbrykiewicz (2018) compreende como idealizadores(as) de novas perspectivas/premissas sobre o objeto biográfico, ela apresenta a sua tese sobre como e, principalmente, o que é o dito "new". A autora defende que a biografia está no meio do caminho entre a ficção e a realidade. Tal pensamento é corroborado por outros estudiosos do tema. Contudo, ela argumenta que a narrativa biográfica contemporânea é uma resposta da pós-modernidade ao estudo do sujeito. Com isso, ela identifica este tipo narrativo como uma bioficção: "A bioficção, por sua vez, sendo um modo de escrita cujo compromisso 'faccional' é limitado, pode ser considerada uma resposta pós-moderna ao desejo biográfico dos leitores, mas é muito mais envolvida na ficção do que em qualquer 
forma anterior de escrita biográfica" (2018, p. 140). Diante das dificuldades de delimitações dos fatos/eventos que compõem uma vida, e, principalmente, a necessidade de uso da ficção para dar sentido a ela, Cymbrykiewicz acredita que somente uma bioficção poderá conceituar o que é conhecido como "new biography".

Para essa historiadora, a "new biography" foi remodelada, buscando responder a questões da pós-modernidade, que identifica no narrador um valor confiável, talvez o único, para ela, neste novo mundo. Diante desse cenário, a narrativa sobre uma vida desaparece para dar lugar ao narrador de uma vida. 0 uso biográfico, para essa autora, remete-se, portanto, a uma nova forma de ver/estudar o sujeito histórico. Ou melhor, na contemporaneidade valoriza-se a narração em detrimento do narrado.

Shubert (2018), apresenta subsídios para compreender a escrita biográfica, pois, partindo de sua trajetória profissional, descreve os caminhos desse gênero na academia, principalmente a de língua inglesa e en passant, do seu país, o Canadá. De certa maneira, segue a mesma linha adotada por Cymbrykiewicz (2018), ao historicizar o gênero biográfico e compreendê-lo à luz da atualidade.

Inicia seu texto destacando que, durante sua formação profissional, nas décadas de 1970/1980, havia no ambiente acadêmico uma relação hostil entre o gênero biográfico e os estudos históricos. Influenciados pela perspectiva francófila da história, viam na biografia uma "histoire événementielle", aspecto que pode ser relacionado ao estruturalismo de Fernand Braudel. Outro olhar historiográfico que influiu na produção acadêmica canadense, neste período, e a qual inspirou diretamente o autor do artigo, foi a História Social, principalmente a escrita pelo inglês E. P. Thompson. Mais uma vertente que não concebia a individualização da história como uma possibilidade de cons- trução do conhecimento histórico (SHUBERT, 2018).

Devido a este ambiente de rejeição à escrita biográfica, Shubert (2018) não se dedicou, sequer pensou em experimentá-la, mesmo que tenha pesquisado sobre diversas vidas em seu doutorado sobre a classe trabalhadora das minas de carvão da região das Astúrias, na Espanha. Descreve que, somente em 2010, começou a escrever a sua primeira biografia, sobre o militar e político espanhol do século XIX, Baldomero Espartero (17931879), publicada em 2018. Durante o processo de escrita desta obra, Shubert relata que leu diversas biografias e, também, sobre o gênero biográfico. Parte da literatura lida continuava a identificar esse gênero narrativo como algo menor ou, "não sendo uma boa maneira de escrever história"13. Mesmo assim, escreve: "Obviamente, opiniões como essas nunca foram unânimes e muitos bons historiadores escreveram biografias",14 inclusive o seu "santo padroeiro pessoal da história social"15, E. P. Thompson, começou sua carreira escrevendo, justamente, uma biografia sobre William Morris (SHUBERT, 2018. p. 197).

O professor Adrian descreve que a biografia continuou a ser questionada dentro da academia, entretanto, o debate começara a ser alterado. Da rejeição, começaram a discutir as possibilidades do gênero. Descreve a proliferação de estudos sobre a biografia neste meio: foram criados periódicos (Journal of Historical Biography) e organizações (Biographers' International Organization) especificamente para debater o fazer biográfico e divulgar os estudos sobre as vidas. Inclusive houvera tentativa de construir uma disciplina própria para a biografia, devido ao seu caráter multidisciplinar (SHUBERT, 2018).

\footnotetext{
13 "not a good way of writing history".

14 "Of course, opinions such as these were never unanimous and many fine historians did write biographies". 15 "personal patron saint of social history".
} 
Para Shubert, é nítida a mudança de atitude dos historiadores(as) em relação à escrita biográfica neste século XXI. Ele relaciona tais alterações a quatro motivações: diferentes correntes historiográficas passaram a discutir o gênero, entre elas a micro história, capitaneada por Carlo Ginzburg, Giovanni Levi e também Natalie Zemon Davis, que "demonstrou que a história de uma vida individual, mesmo a mais obscura, pode iluminar o passado e permitir que historiadores sérios alcancem um público mais amplo".16 A segunda razão apontada por ele é, ironicamente, o interesse pelas subjetividades das individualidades da nova História Social, pois essa abordagem "oferece uma das melhores maneiras de explorá-los".7 A terceira motivação está relacionada à crítica estruturalista, pois, identificaram que "A vida das pessoas nem sempre foi restringida pelas fronteiras políticas; a vida individual também se tornou uma maneira importante de explorar os novos campos vitais da história transnacional, global e mundial"18 Esses pressupostos, segundo o historiador, estão relacionados diretamente ao estudo da história. A quarta razão foi mais abrangente, levando a uma crise das ciências humanas e sociais como um todo, e influenciou diretamente nas motivações detalhadas acima: a individualização pós-moderna, acelerada com a crise do marxismo, pós-muro de Berlim, fora um fator exponencial para o crescimento do interesse acadêmico pela subjetividade dos sujeitos históricos, transformando a biografia como lugar de destaque desta abordagem, pois ela, por privilegiar as narrativas sobre a vida, possuiria técnicas que corroborariam neste trabalho.

16 "demonstrated that the story of an individual life, even the most obscure, can both illuminate the past and allow serious historians to reach a wider audience".

17 "offers one of the best ways to explore them".

18 "people's lives were not always constrained by political borders, the individual life has also become an important way of exploring the vital new fields of transnational, global, and world history"
Todavia, não foi somente esta a razão do interesse da academia pelo biográfico, segundo Shubert (2018, p. 199):

Em geral, tem havido uma nova preocupação com as maneiras pelas quais, como Lois Banner coloca, "a biografia interage com a história da era [do sujeito]", tem sido reconhecida como um veículo poderoso para entender os processos mais amplos da sociedade, cultura e política em tempos e lugares passados, que são o assunto usual do historiador. A biografia não significa mais automaticamente uma narrativa direta do começo ao fim da vida de um grande homem ou, muito menos frequentemente, de uma mulher. Agora existe uma variedade muito maior de assuntos e maneiras de abordar suas vidas $^{19}$

O interesse maior pela narrativa biográfica levara a mudanças na epistemologia desta abordagem, favorecendo novas metodologias para o seu uso, segundo o autor. Nesse sentido, compreendemos que se trata de um desdobramento do contexto vivenciado. Tais alterações na forma de trabalhar com a narrativa biográfica não estariam entrelaçadas com a individualização do social? Acreditamos que sim, pois as formas explicativas da história, em crise, não conseguiam atender às expectativas geradas neste campo do conhecimento. Sem atender às necessidades do presente, buscou-se novos meios, técnicas, abordagens, metodologias para atender a esse novo cenário, com novas inquietações. Aparentemente, diverge de Cymbrykiewicz (2018) em relação às motivações para estes usos biográficos: não se trata da valorização da narração sobre o narra-

19 "In general, there has been new concern for the ways in which, as Lois Banner put it, "biography interacts with the history of [the subject's] era", has been recognized as a powerful vehicle for understanding the larger processes of society, culture and politics in a past time and place that are the historian's usual subject. Biography no longer automatically means a straightforward cradle-to-grave narrative of the life of a great man or, much less frequently, woman. There is now a much greater variety of subjects and ways of approaching their lives". 
do, e sim, sobre forma e a epistemologia desta narração, que fornecem respostas às questões contemporâneas.

A relação entre a história e a biografia tem sido, em sua maior parte, desde o processo de cientifização da história, marcada pela rejeição da primeira à segunda. A conciliação ainda está tímida. Todavia, é inegável a importância do biográfico para a escrita da história, nestas primeiras décadas do século XXI. Conseguimos identificar neste texto, o que pensam (parte) dos(as) historiadores(as) de língua inglesa sobre o tema. Mas há, neste meio, projetos que buscam uma independência biográfica, ou seja, a criação de uma disciplina própria. Não há, portanto, uma definição neste campo, quanto aos usos, limites e epistemologia da biografia.

Schmidt (2017), em um texto-síntese, no qual realizou comentários relacionados aos artigos publicados no dossiê Biografismo, da Revista Diálogos, no ano de 2017, apresenta uma breve discussão sobre os questionamentos que temos apresentado. Para além de uma perspectiva classificatória, ou em busca de constituir a narrativa biográfica como uma escrita historiográfica, Schmidt destaca que esse gênero é "praticado em vários campos de produção discursiva, como o Jornalismo, a Literatura, o Cinema, e Antropologia e a História, entre outros" (SCHMIDT, 2017, p. 47). O historiador, citando François Dosse, classifica a escrita biográfica como um gênero híbrido, justamente por essa intersecção entre estes diversos campos. Entretanto, ele defende que essa forma de escrita:

Exige do biógrafo muita consciência de seus recursos narrativos, pois são eles que configuram o/a personagem que se quer analisar. Tais recursos não dizem respeito apenas à forma, mas às próprias escolhas epistemológicas do/a autor/a. Assim, por exemplo, a utilização de flashbacks e diálogos, tão comum nas biografias literárias e jornalísticas, pode ser de grande valia às biografias históricas, para se expressar, por exemplo, o tempo da memória e as relações dos indivíduos com os/as seus/suas contemporâneos/as. Como fazer isso sem romper com os protocolos da operação historiográfica? O lugar acadêmico teria flexibilidade suficiente para permitir ousadias? Georges Duby dispensou as notas e imaginou diálogos em seu Guilherme Marechal (1987) e Natalie Davis (2007) permitiuse ela própria dialogar com suas personagens do século XVII, mas isso seria possivel aos/às jovens historiadores/as que escrevem suas dissertações e teses? (SCHMIDT, 2017, p. 48)

Essa interrogação no final do trecho, nos devolve a realidade acadêmica no campo da História. Para o autor, há certo desconforto para o(a) historiador(a) utilizar de ferramentas literárias, principalmente a ficção, para dar cabo à narração sobre uma vida. Ele esclarece que por ser o biógrafo que configura o personagem narrado, isso pode implicar, diretamente, com princípios da operação historiográfica (CERTEAU, 1982). Tal situação, pode levar a um questionamento acadêmico do saber construído por meio da narrativa biográfica.

Nesse mesmo texto, identificamos outro problema biográfico: "é possível narrar uma vida 'toda', ou o que se conta é sempre uma seleção, mais ou menos arbitrária, de certos acontecimentos de existência?". O professor Benito defende que a escrita biográfica, mesmo com suas peculiaridades, pode abrigar em sua narrativa os problemas historiográficos: “qual biografia feita por historiadores/as na atualidade separa indivíduo e sociedade? [...] porque uma biografia tem que contar necessariamente uma vida do começo ao fim?" ( $\mathrm{SCH}-$ MIDT, 2017, p. 45).

Resumidamente, esse historiador defende que o uso biográfico não necessita estar atrelado e engessado pela cronologia de uma vida. A questão temporal/cronológica deve ser um instrumento para respostas aos problemas historiográficos e não o modal da narrativa. Sendo assim, para Schmidt, a biografia possui 
sua relevância por poder integrar e interligar o sujeito aos mais diversos espaços e áreas do conhecimento, favorecendo um olhar singular da história. A hibridez, nesse caso, não seria um problema e sim, uma ferramenta para a escrita da história.

Avelar (2017), em seu artigo "Escrita biográfica e escrita da história no pensamento de Wilhelm Dilthey", apresenta as perspectivas biográficas presentes na trajetória intelectual do filósofo alemão. Após apresentar as problemáticas envolvendo a narrativa biográfica na contemporaneidade, pois, segundo Avelar, essa forma de escrever sobre vidas é descrita como "desafiadora" e "problemática" por parte do mundo acadêmico, principalmente, no campo da história, ele traz ainda a discussão, bastante disseminada neste ambiente, quanto à possibilidade de ter acesso à verdade por meio da narrativa biográfica. Faz uma rápida abordagem histórica, quanto a essa possibilidade:

Entre os antigos, havia a percepção de que os dois gêneros eram congruentes em seus objetivos de fornecer bons exemplos morais à posteridade, ainda que ao historiador fosse interditada a faculdade da imaginação, plenamente admitida aos biógrafos. Estes, por essa razão, não narravam a história, mas 'vida'. Essa perspectiva que aproximava e, simultaneamente, afastava história e biografia persistiu ao longo da Idade Média, especialmente no tocante à vida dos santos, as conhecidas hagiografias com notável fundo normativo. (AVELAR, 2017, p. 122)

Diante desse quadro, Avelar buscou nos escritos de Dilthey, ideias, conceitos e concepções que vão além de narrar sobre acontecimentos de uma vida. Ele parte da hipótese inicial de que, para o filósofo alemão, "o mundo histórico é reconhecível nas expressões dos indivíduos, ou seja, em suas ações, sentimentos e constrangimentos" (AVELAR, 2017, p. 121). Dentro dessa perspectiva, o sujeito histórico seria um prisma visualizável daquilo que já foi. Ao analisarmos suas ações/percepções, poderíamos construir parte do passado perdido. Apesar dessa leitura, para o filósofo alemão, a realidade histórica não se "reduz às experiências de indivíduos". Partindo da premissa hermenêutica de Dilthey, segundo o historiador brasileiro, "a experiência humana exprime o ponto de acesso fundamental para a compreensão do mundo histórico", todavia "a ordem do mundo físico não se desvincula do homem" (2017, p. 121). O sujeito histórico está inserido no mundo, bem como o mundo está presente nesta experiência individual. Nesta relação dialética, encontra-se a realidade histórica:

Ela [realidade histórica] deve ser encontrada nas expressões da vida, variáveis, obviamente, em função das épocas e dos sistemas de valores reinantes [...]. A particularidade não desautoriza a objetividade, a verdade e a confiabilidade histórica [...] 0 particular é a universalidade possivel. A consciência histórica desmistifica a escala extrínseca de valores e reconhece o pluralismo e a existência de uma diversidade ampla de visões de mundo historicamente determinadas. A parcialidade das verdades contidas em cada contexto é a condição para a apreensão da totalidade do processo histórico. (AVELAR, 2017, p. 129)

Essa perspectiva biográfica de Dilthey busca, através do conhecimento da vida de um determinado indivíduo, ter acesso a determinado contexto histórico; porém, não se trata de um retrato fiel de um passado, ou, um sujeito-modelo, o qual, seria, quase, uma metonímia: ao conceber a vida de determinando homem ou mulher, teríamos acesso à vivência e experiência da coletividade de um certo momento histórico. Avelar busca justamente apresentar que, na concepção do filósofo alemão, os sujeitos históricos são fragmentos do passado. Organizando-os teríamos reflexos, a construção de uma realidade e não a realidade histórica. Biografar, nesse sentido, é evidenciar a 
particularidade diante da universalidade: "em Dilthey, a biografia surge como o aspecto elementar de toda realidade histórico-social, a forma mais sensivel de compreensão filosófica" (2017, p. 131).

Tal cenário que estamos descrevendo pode se apresentar como aporético, pois, a biografia somente possui validade ao representar determinado período histórico. Porém, tal contexto é vivenciado e experienciado diferentemente por cada indivíduo. Essa perspectiva, segundo Avelar, parte de uma "tentativa original de conciliar de maneira consequente duas abordagens - a individualista e a holista - do mundo histórico" (2017, p. 135). Esse historiador descreve a concepção de Dilthey em relação à narrativa biográfica:

Os sentidos e os padrões são construídos pelos próprios sujeitos em suas expressões históricas e experiências. A sequência em que tais experiências se configuram no tempo é explicitada por dois fatores: a memória e a antecipação do futuro. Essas articulações entre passado, presente e futuro vão constituindo os padrões com os quais os homens se defrontam em suas relações uns com os outros. (AVELAR, 2017, p. 135)

A perspectiva ao mesmo tempo individual e holística de Dilthey, para o professor Alexandre, é uma das grandes contribuições desse filósofo tanto para o gênero biográfico quanto para a aproximação deste do campo historiográfico: "só há compreensão por intermédio de sentidos mínimos partilhados, e só há interpretação por meio da existência de diferenças. Esse ciclo hermenêutico torna a biografia não apenas possivel, mas o 'espírito de uma época"' (AVELAR, 2017, p. 140, grifos do autor). Essas preocupações foram abordadas, parcialmente, pelo mesmo autor no artigo "O reencontro com o General: relendo uma tese nove anos depois". O objetivo principal deste texto fora revisitar as motivações/justificativas para a construção de uma tese sobre o general Ed- mundo de Macedo Soares, a qual Avelar defendeu junto à Universidade Federal Fluminense (UFF) no ano de 2006. Ao retomar essa leitura, as mudanças de perspectivas e abordagens sobre o fazer biográfico o levaram a questionamentos acerca dessa forma narrativa. Vejamos.

Avelar reafirma, neste escrito, as incertezas que acompanham as discussões teóricas e metodológicas do gênero biográfico no presente. Contudo, ele descreve que a "biografia é um gênero de grande interesse exatamente por sua capacidade de desestabilizar as oposições entre o ser e o mundo, literatura e história, fato e ficção, sujeito e objeto" (AVELAR, 2017b, p. 4). É nítida a premissa de uma narrativa híbrida, da qual parte o historiador para pensar/ escrever uma obra biográfica. Ao se posicionar dessa maneira, então, descreve o percurso de desenvolvimento de sua tese. Esse caminho, pelo seu testemunho, fora de tentar ajustar suas preocupações, questionamentos, curiosidades e documentação à operação historiográfica. Avelar enquadrou o seu personagemfonte a esses paradigmas, contextualizando-o, delimitando a temporalidade, apresentando um problema-hipótese, construindo uma justificativa para a realização desta pesquisa/escrita. Contudo evitou escrever uma biografia, apresentando sua pesquisa como história social da biografia.

Em suas considerações finais, o historiador destaca, ao olhar para trás, para o seu passado, para a trajetória de sua pesquisa doutoral, certa ingenuidade com tais problematizações e delimitações. Pois, seguindo suas palavras: "é no ato de escrita que se forma o espaço privilegiado para a investigação das relações entre ficção e história". Apesar de todos nossos cuidados, seja como historiadores(as) ou biógrafos(as), ao mediarmos, tanto nossa investigação, quanto o resultado dela, por meio da escrita, estamos implicados à necessidade de fazer sentido, e, com isso, entra, quase 
como uma questão impositiva, a ficção: "o caráter 'problemático' da biografia, está, a meu ver, marcado, entre outras razões, pela própria dificuldade dos historiadores em conceber a escrita como uma dimensão incontornável do seu trabalho e ato performativo" (AVELAR, 2017b, p. 11).

Estas complicações, por mais que façam parte do trabalho do(a) historiador(a), devido às normativas, discussões teóricas e metodológicas e validações acadêmicas, acabam por enquadrar nossos estudos/textos a tais critérios. Todavia, a narrativa biográfica possui vida própria, e, para que ela possa ter o resultado esperado, e, principalmente, ter um significado e uma recepção por parte dos leitores, tais preocupações acadêmicas-científicas, acabam se equilibrando às necessidades narrativasficcionais:

Espera-se de uma biografia a comprovação documental da descrição da vida do personagem e o seu registro em quadros contextuais que 0 localizem, emprestando sentido às suas ações e feitos. No alinhamento a uma concepção que valoriza tanto a veracidade extraída das fontes quanto a força imaginativa da narração, as noções de contexto e documento, tradicionalmente empregadas pelos biógrafos, conformam uma temporalidade dialógica e intempestiva que explora o passado de maneira tal que ele não atua simplesmente como causa ou precedente do presente, mas se mostra disposto a invadir, alarmar, dividir e desapropriar o lugar em que o atual se determina no futuro. (AVELAR, 2017b, p. 11-12)

Dois elementos essenciais para a operação historiográfica, que são, por si só complicadores para a escrita da história, são ainda mais complexos e fluídos para a escrita biográfica: o contexto e o documento. Avelar situa as discussões de Dominick LaCapra quanto à fragilidade do contexto: "texto e contexto são suplementares entre si, se adicionam, substituindo e suprindo faltas e ausências mutua- mente, fornecendo o excesso que é preciso ao processo de interpretação"; também traz as limitações do documento, na perspectiva de Le Goff: "o que está presente no documento - seu aspecto informacional - mescla-se com o que não está ou com que poderia ter estado. 0 que nele há se combina com o desejo do que poderia estar" (AVELAR, 2017b, p. 12).

Identificamos neste artigo inquietações e uma quase aporia para a escrita biográfica, ao buscarmos enquadrá-la a uma operação historiográfica. Todavia, tais problemáticas elencadas por Avelar, também destacadas pelos autores anteriores, não o impediram de escrever e defender uma tese doutoral, ancorada na vida de um personagem histórico. 0 uso biográfico também é válido para uma pesquisa social intelectual, como perceptivel.

o último artigo que vamos analisar aqui, é de autoria Delory-Momberger (2016), intitulado "A pesquisa biográfica ou a construção compartilhada de um saber do singular", publicado nesta revista no ano de 2016. Logo no início do texto, a autora diz que "não terminamos ainda de questionar o que fundamenta o projeto e o processo da pesquisa biográfica, de identificar sua especificidade e, portanto, sua autonomia em relação a outras correntes das ciências humanas e sociais" (2016, p. 135). Percebe-se que há uma busca em construir um campo autônomo para o objeto biográfico. E o objetivo da autora nesse texto foi verificar a epistemologia deste campo e o lugar do fato biográfico "nos processos de individuação e de socialização" da pesquisa biográfica (2016, p. 133).

Para Delory-Momberger, o campo biográfico compartilha seus pressupostos com outras áreas do conhecimento, contudo, ela reitera que "a entrada específica da pesquisa biográfica, seu foco e o saber que ela procura diz respeito ao biográfico enquanto dimensão constitutiva da gênese e do tornar-se sócio 
individual" (2016, p. 136, grifos da autora). Portanto, para autora, este tipo investigativo não busca compreender o sujeito diante das estruturas ou a individualização para um estudo meramente clínico para compreensão do ser, enquanto ser, e sim, como possibilidade de identificar a gênese (ou o constituir-se sujeito) de uma sociedade, por ele mesmo. Dá-se, dessa forma, uma relação dialética entre sujeito e sociedade, este se constrói como indivíduo nesta relação, mas sua experiência é única, e por isso a importância de a narrar.

Uma das diferenciações da perspectiva biográfica para outras formas de escrever sobre vidas, para Delory-Momberger, trata-se da introdução temporal na narrativa, ou, o que ela chama de "temporalidade biográfica": "uma dimensão constitutiva da experiência humana, por meio da qual os homens dão forma ao que vivem" (2016, p. 136). Portanto, a narrativa biográfica é rica, não somente pelos detalhes e compreensão do indivíduo, mas principalmente, pela sua capacidade de inteligibilidade do tempo. Por isso, segundo a autora, a "dimensão biográfica deve assim ser entendida como uma elaboração cumulativa e integrativa da experiência segundo uma hermenêutica que faz da trama narrativa seu modo da apreensão e de inteligibilidade da vida" (2016, p. 136).

A biografia, nessa perspectiva apresentada pela autora, permite melhor ver/visualizar o indivíduo em sua construção temporal, a partir de suas narrativas, ou de narrativas sobre ele, pode-se ver a ação, o agir, a construção do sujeito social-temporal. Dessa maneira, a “biografização surge como uma hermenêutica prática, um quadro de estruturação e de significação da experiência exercendo-se de forma constante na relação do homem com a sua vivência e com seu ambiente social e histórico" (DELORY-MOMBERGER, 2016, p. 139).

$A$ mediação entre a experiência humana e o seu conhecimento, se dá por meio da narra- tiva. Nela, segundo a autora, que se dá a "dimensão performativa", produzindo a ação, o agir humano. A narrativa "não é então apenas o produto de um 'ato de narrar', ela tem também um poder de efetivação sobre o que ele narra". E tal característica é o que "fundamenta o interesse principal da pesquisa biográfica para narrativa", pois, é por meio destas "operações de configuração e de metabolização que implementa, é um poderoso 'ator' de biografização" (DELORY-MOMBERGER, 2016, p. 141).

É devido a essas características do objeto biográfico (ou seria melhor, da narrativa biográfica?), que o(a) pesquisador(a) do campo encontra uma riqueza de possibilidades na pesquisa biográfica, pois, ela possibilita "tentar entender como a narrativa ao mesmo tempo produz e permite vislumbrar a construção singular que um indivíduo faz de uma existência e de uma experiência, elas também singulares, que integram e se apropriam desses elementos coletivo" (DELORY-MOMBERGER, 2016, p. 142).

Nas considerações finais do texto, a autora apresenta o que compreende como a possibilidade do objeto biográfico ser lugar de saber compartilhado, privilegiado e original para compreender a formação individual dos seres humanos:

Se a 'fala de si', sob todos os seus registros e em todas as suas diversidades, constitui o material privilegiado de um saber biográfico, ela é também o vetor pela qual os seres humanos acessam a um saber e a um poder deles mesmos que lhes dão a capacidade de se desenvolver e de agir enquanto 'sujeitos' no meio dos outros e no seio da cidade. (DELORY-MOMBERGER, 2016, p. 145)

A pesquisa biográfica, para autora, é um local no qual podemos compreender, por meio das narrativas, as “dimensões constitutivas do fato e do tornar-se humanos: no espaço-social e no tempo-existência" (DELORY-MOMBERGER, 
2016, p. 145). Ou, é um saber no qual compreende a formação educativa do ser, o que garantiria a possibilidade de um campo autônomo e frutífero para as humanidades.

A autora é professora de Ciências da Educação da Universidade de Paris-XIII. Seu campo de atuação/investigação é, portanto, o da educação. E, como podemos perceber, consegue descrever mais certezas sobre o objeto biográfico, como pesquisa e narrativa de um saber, do que o campo historiográfico.

\section{Considerações finais}

A miríade de explicações sobre o objeto biográfico nos artigos acima, nos esclarece quanto a dificuldade de situá-lo no âmbito acadêmico, como escrita da história. Provavelmente porque a preocupação da historiografia para com esse gênero seja relativamente recente e consequência da mudança na forma de visualizarmos o sujeito histórico, que, segundo Shubert (2018), e até mesmo Cymbrykiewicz (2018), está diretamente relacionada à intensificação da individualização, principalmente, na perspectiva pós-moderna. Somado a isso, a busca por construir a narrativa biográfica como uma escrita interdisciplinar, para Moreira e Caballé (2018), é um complicador para edificar uma epistemologia do campo, contrariando, de certa maneira, a perspectiva apresentada por Benito Schmidt, que vislumbra na biografia um gênero híbrido, intersecção entre várias áreas do conhecimento, o que facilitaria a sua utilização como escrita historiográfica. Burdiel (2014a) apresenta tal dinamismo, destacando que há várias formas de abordar o "eu". Assim, ela alarga o conceito de biografia para além da narrativa sobre a trajetória de uma vida. Todos esses predicados, no entanto, são qualidades do gênero e potencialidades para seu uso como escrita da história. Todavia, Alexandre Avelar destaca problemas que podem atin- gir, diretamente, a operação historiográfica: a maior dificuldade para lidar com o documento e o contexto na narrativa biográfica, a coloca em uma quase aporia.

Shubert (2018) toca em um ponto fundamental: há uma busca em construir um campo autônomo para o objeto biográfico, inclusive com a organização de eventos, periódicos e associações. Moreira e Caballé (2018) destacam a importância da construção de uma epistemologia biográfica. E o texto final, Delory-Momberger (2016), apresenta tais pressupostos epistemológicos, destacando a importância do biográfico como um saber e um campo investigativo.

Trouxemos nesta análise bibliográfica, uma pequena amostra do debate contemporâneo sobre a biografia, especialmente no campo historiográfico. Contudo, mesmo diante dos limites, tanto dos textos selecionados, quanto das páginas para escrever este texto, concluímos que a biografia possui vida própria e ela não é e não poderá ser refém da historiografia ou de qualquer outro campo do conhecimento. Há frutíferas iniciativas, a nível internacional, que demonstram essa importância, atualidade e possibilidade de autonomia do objeto biográfico: além das citadas Biographers' International Organization e Journal of Historical Biography, há também a The Biography Society, uma organização de pesquisadores(as) do campo, cujo o propósito é o debate e publicação de teorias e metodologias da pesquisa biográfica. Essa sociedade organiza eventos e mantém um periódico visando tais fins. Entre os associados dessa instituição, estão renomados professores(as) da História, como Dosse (2009), Moreira e Caballé (2018). No Brasil, temos a Associação Brasileira de Pesquisa (Auto) Biográfica (BIOGraph) ${ }^{20}$, que também promove eventos e mantém este periódico Revista Brasileira de Pesquisa (Auto)Biográfica, que publi-

20 Para maiores informações: http://www.biograph.org.br/. 
ca e promove a pesquisa no campo biográfico brasileiro.

Diante deste cenário de avanço nas teorias, metodologias e epistemologias sobre pesquisas biográficas, é necessário o campo historiográfico intensificar o debate sobre o lugar da biografia na escrita da História, buscando contribuições de outras áreas, seja da Educação, da Literatura, ou até mesmo, da própria Biografia.

\section{Referências}

ASOCIACIÓN DE HISTÓRIA CONTEMPORÁNEA; MARCIAL PONS HISTORIA. Ayer. Madrid, AHC, v. 93, n. 1, p. 1-7. 2014. Disponivel em: http://revistaayer.com/ anteriores/307. Acesso em: 15 out. 2019.

AVELAR, Alexandre de Sá. Escrita Biográfica e escrita da história no pensamento de Wilhelm Dilthey. Dimensões. Vitória-ES, v. 38, p. 120-142. jan-jun 2017. Disponivel em: http://www.periodicos.ufes.br/dimensoes/article/view/16809. Acesso em: 15 out. 2019.

AVELAR, Alexandre de Sá. O reencontro com o General: relendo uma tese nove anos depois. Diálogos. Maringá, UEM, v. 21, no 2, 2017b, p. 3-14. Disponível em: http://www.periodicos.uem.br/ojs/index.php/ Dialogos/article/view/39523. Acesso em: 15 out. 2019.

ARFUCH, Leonor. 0 espaço biográfico: dilemas da subjetividade contemporânea. Rio de Janeiro: EdUERJ, 2010.

BURDIEL, Isabel. Historia Política y biografia: más allá de las fronteras. Ayer. v. 93, no 1 p. 47-83, $2014 a$. Disponivel em: http://revistaayer.com/anteriores/307. Acesso em: 15 out. 2019.

BURDIEL, Isabel. Presentación. Ayer. Madrid, AHC, v. 93, no 1, p. 13-18, 2014b. Disponivel em: http:/ / revistaayer.com/anteriores/307. Acesso em: 15 out. 2019.

CERTEAU, Michel. A Escrita da História. Rio de Janeiro: Forense Universitária, 1982.

CYMBRYKIEWICZ, Joanna. How new is the new bio- graphy? Some Remarks on the misleading term's past and present. Studia Europaea Gnesnensia. v. 18, p. 129-146, 2018. Disponivel em: https://steurgn. pl/portal/joanna-cymbrykiewicz.pdf. Acesso em: 15 out. 2019.

DELORY-MOMBERGER, Christine. A pesquisa biográfica ou a construção compartilhada de um saber do singular. Revista Brasileira de Pesquisa (Auto)Biográfica. Salvador, BIOgraph, v. 01, no 01, p. 133-147, jan./abr. 2016. Disponível em: https://www.revistas. uneb.br/index.php/rbpab/article/view/2526. Acesso em: 01 jun. 2020.

DELORY-MOMBERGER, Christine. Fundamentos epistemológicos da pesquisa biográfica em educação. Educação em Revista. Belo Horizonte, UFMG, v. 27, no 01, p. 333-346. abr. 2011. Disponivel em: https:// www.scielo.br/pdf/edur/v27n1/v27n1a15.pdf. Acesso em: 01 jun. 2020.

DOSSE, François. 0 Desafio Biográfico: Escrever uma Vida. São Paulo: Editora da Universidade de São Paulo, 2009.

LEVI, Giovanni. "Usos da biografia". In: FERREIRA, Marieta; AMADO, Janaína. Usos \& abusos da história oral. Rio de Janeiro: FGV, 2003. p. 167-182.

LEVILLAIN, Philippe. Os protagonistas: da biografia. In: RÉMOND, René. Por uma história política. Rio de Janeiro, RJ: Editora FGV, 2003. p. 141-184.

LORIGA, Sabina. 0 pequeno $X:$ da biografia à história. Belo Horizonte: Autêntica Editora, 2011.

MOREIRA, Maria Eunice; CABALLÉ, Anna. A hora da biografia. Letras de Hoje. Porto Alegre, PUCRS, v. 53, no 2, p. 187-189, 2018. Disponivel em: http://revistaseletronicas.pucrs.br/ojs/index.php/fale/article/ view/31525/17035. Acesso em: 15 out. 2019.

PINEAU, Gaston. As histórias de vida em formação: gênese de uma corrente de pesquisa-ação-formação existencial. Educação e Pesquisa. São Paulo, FEUSP, v. 32, no 2, p. 329-343. mai./ago. 2006. Disponivel em: https://www.scielo.br/pdf/ep/v32n2/ a09v32n2.pdf. Acesso em: 01 jun. 2020.

REVEL, Jacques. História e historiografia: exercícios críticos. Curitiba-PR: Ed. UFPR, 2010. 
SCHMIDT. Benito Bisso. Os múltiplos desafios da biografia ao/à historiador/a. Diálogos. Maringá, UEM, v. 21, no 2, p. 44-49, 2017. Disponivel em: http:// periodicos.uem.br/ojs/index.php/Dialogos/article/ view/39527. Acesso em: 15 out. 2019.

SHUBERT, Adrian. What do historians really think about biography? Letras de Hoje. Porto Alegre, PUCRS, v. 53, no 2, p. 196-202, 2018. Disponivel em: http:// revistaseletronicas.pucrs.br/ojs/index.php/ fale/article/view/31498. Acesso em: 15 out. 2019.

XAVIER, Antônio Roberto; VASCONCELOS, José Gerardo; VALE XAVIER, Lisimére Cordeiro do. Biografia e educação: aspectos histórico-teórico-metodológico. Revista Brasileira de Pesquisa (Auto)Biográ-

fica. Salvador, BIOgraph, v. 03, no 09, p. 1016-1028, set./dez. 2018. Disponivel em: https:/ / www.revistas. uneb.br/index.php/rbpab/article/view/5607. Acesso em: 01 jun. 2020.

\section{Sites}

UNIVERSIDADE DE SÃO PAULO. Instituto de Estudos Brasileiros. História e Biografia: Perspectivas para os Estudos Brasileiros. Disponivel em: <https:// uspdigital.usp.br/jupiterweb/obterDisciplina?sgldis=IEB0262\&verdis=1>. Acesso em: 10 jun. 2019.

UNIVERSIDADE DE SÃO PAULO. Instituto de Estudos Brasileiros. Memorialismo Brasileiro: Autobiografia. Disponivel em: <https://uspdigital.usp.br/jupiterweb/obterDisciplina?sgldis=|EB0255\&verdis=1>. Acesso em: 10 jun. 2019.

UNIVERSIDADE DO ESTADO DA BAHIA. Programa de Pós-graduação em Educação e Contemporaneidade. Estrutura Curricular. Disponivel em: <https:// portal.uneb.br/ppgeduc/estrutura-curricular/>. Acesso em 04 jun. 2020.

UNIVERSIDADE ESTADUAL DE CAMPINAS. Instituto de Filosofia e Ciências Humanas. Disciplinas. Disponivel em: <https://www.ifch.unicamp.br/ifch/timegrid/graduacao/disciplinas>. Acesso em:10 jun. 2019.

UNIVERSIDADE ESTADUAL DE CAMPINAS. Instituto de Filosofia e Ciências Humanas. Programa de Pós-
Graduação em História. Disciplinas. Disponivel em: <https://www.ifch.unicamp.br/ifch/pos/historia/ disciplinas>. Acesso em: 10 jun. 2019.

UNIVERSIDADE FEDERAL DO CEARÁ. Programa de Pós Graduação em Educação. Discentes. Lista de Oferta de Disciplinas no Semestre. Disponivel em: <https://www.ppge.ufc.br/ppge/wp-content/ uploads/2017/02/Oferta-de-Disciplinas-2019.1.pdf>. Acesso em 04 jun. 2020

UNIVERSIDADE FEDERAL DE MATO GROSSO. Matriz Curricular dos cursos de graduação. Disponivel em: <http://sistemas.ufmt.br/matrizcurricular/>. Acesso em: 10 jun. 2019.

UNIVERSIDADE FEDERAL DE MATO GROSSO. Quadro de disciplinas ofertadas pelo Programa de PósGraduação em História (2018/2). Disponível em: <http://ppghis.com/ppghis/o-programa/disciplinas-do-semestre/doutorado.html>. Acesso em: 10 jun. 2019.

UNIVERSIDADE FEDERAL DE PERNAMBUCO. Departamento de História. Horário 2017/1. Disponivel em: <https:// www.ufpe.br/documents/39423/388656/ HOR\%C3\% 81RIO+2017.1.pdf/9 c05bda2-0027-43ef-99b0-751d10a1847f>. Acesso em: 10 jun. 2019.

UNIVERSIDADE FEDERAL DE PERNAMBUCO. Programa de Pós-Graduação em História. Grade Curricular. Disponivel em: <https://www.ufpe.br/ppghistoria/ grade-curricular>. Acesso em: 10 jun. 2019.

UNIVERSIDADE FEDERAL DO RIO DE JANEIRO. Instituto de História. Ementas das disciplinas de graduação. Disponivel em: <http://historia.ufrj.br/>. Acesso em: 10 jun. 2019.

UNIVERSIDADE FEDERAL DO RIO DE JANEIRO. Programa de Pós-Graduação em História Social. Disciplinas. Disponivel em: <https://www.ppghis.historia. ufrj.br/disciplinas/>. Acesso em: 10 jun. 2019.

UNIVERSIDADE FEDERAL FLUMINENSE. Bacharelado em História. Disponivel em: <http://www.historia. uff.br/grad/files/2013_flux_bacharelado.pdf>. Acesso em: 10 jun. 2019.

UNIVERSIDADE FEDERAL FLUMINENSE. Licenciatura em História. Disponivel em: <http://www.historia. 
uff.br/grad/files/2013_flux_licenciatura.pdf>. Acesso em: 10 jun. 2019.

UNIVERSIDADE FEDERAL FLUMINENSE. Programa de Pós-graduação em História. História e Biografia. Lima Barreto, José Saramago, Edgar Rodrigues. Disponivel em: <http://www.historia.uff.br/stricto/ cursos_detalhe.php?cod_curso=1273>. Acesso em: 10 jun. 2019.

UNIVERSIDADE FEDERAL RURAL DO RIO DE JANEIRO. Graduação em História. Disciplinas obrigatórias. Disponível em: <http://cursos.ufrrj.br/grad/histo- $\mathrm{ria/disciplinas-obrigatorias/>.} \mathrm{Acesso} \mathrm{em:} 10$ jun. 2019.

UNIVERSIDADE FEDERAL RURAL DO RIO DE JANEIRO. Programa de pós-graduação em História. Quadro de horário de disciplinas (2019/1). Disponivel em: <http://cursos.ufrrj.br/posgraduacao/pphr/files/2019/02/1-Quadro-de-hor\%C3\%A1rios-disciplinas-2019-1.pdf>. Acesso em: 10 jun. 2019.

Recebido em: 27.12.2019

Revisado em: 02.06.2020

Aprovado em: 03.06.2020

Mauro Henrique Miranda de Alcântara é doutor em História pela Universidade Federal de Mato Grosso (UFMT). Realizou estágio doutoral na Universidad de Buenos Aires. Professor do Instituto Federal de Rondônia (IFRO), Campus Cacoal. E-mail: alcantara.mauro@gmail.com 